\title{
POPULAÇÃO DE PLANTAS E ESPAÇAMENTO ENTRE LINHAS DO FEIJOEIRO IRRIGADO. I: COMPORTAMENTO MORFOLÓGICO DAS PLANTAS
}

\section{PLANT POPULATION AND ROW SPACING FOR IRRIGATED DRYBEAN. I: PLANT MORPHOLOGICAL CHARACTERISTICS}

\author{
Sidnei Osmar Jadoski ${ }^{1}$ Reimar Carlesso $^{2}$ Mirta Teresinha Petry ${ }^{3}$ \\ Dolores Woischick ${ }^{4}$ Leandro Cervo ${ }^{4}$
}

RESUMO

O experimento foi conduzido com o objetivo de avaliar variações no índice de área foliar, altura das plantas, número de nós, comprimento dos entrenós na haste principal e altura das vagens em relação à superfície do solo do feijoeiro irrigado e cultivado em diferentes populações de plantas $e$ espaçamentos entre linhas de cultivo. $O$ experimento foi conduzido no ano agrícola 1997/98, em área experimental do Departamento de Engenharia Rural da Universidade Federal de Santa Maria, Santa Maria, RS. A cultivar de feijão preto BRFEPAGRO 44 - Guapo brilhante, de crescimento indeterminado (tipo II), foi cultivada em três populações de plantas $(175,250 \mathrm{e}$ 325 mil plantas há ${ }^{-1}$ ) e três espaçamentos entre linhas de cultivo $(35,50$ e $65 \mathrm{~cm})$. Utilizou-se o delineamento experimental inteiramente casualizado, bifatorial, com quatro repetições. Irrigações por aspersão foram aplicadas quando a evapotranspiração máxima da cultura, estimada com base na evaporação do tanque classe "A", indicava um valor acumulado de $25 \mathrm{~mm}$. Os resultados demonstraram que o aumento da população de plantas ocasionou aumento no índice de área foliar durante a fase de crescimento vegetativo da cultura, sendo que na fase reprodutiva, o índice de área foliar foi afetado pelo espaçamento entre as linhas de cultivo. A área foliar, a altura de plantas e o número de nós na haste principal aumentaram com a redução na população de plantas. A altura da extremidade da primeira vagem das plantas em relação ao solo apresentou comportamento quadrático com o aumento na população de

\begin{abstract}
plantas. Os diferentes espaçamentos e populações de plantas não afetaram o comprimento dos entrenós na haste principal das plantas.
\end{abstract}

Palavras-chave: irrigação, sistema de cultivo, feijão, colheita SUMMARY

The objective of this experiment was to evaluate changes in leaf area index, plant height, number of nodes, internode length and legumes height above soil surface of drybean plants cultivated in different plant populations and row spacings. The experiment was conducted during 1997/98 growing season in the experimental field of the Rural Engineering Department ofthe Federal University of Santa Maria, Santa Maria - RS, Brazil. The drybean cultivar BR-FEPAGRO 44 - Guapo brilhante, (type II) was submitted to three plant populations $(175,250$ and 325 thousand plants $\left.\mathrm{a}^{-1}\right)$ and three row spacing $(35,50$ and $65 \mathrm{~cm}) . A$ completely randomized design, factorial, was used with four replications. Sprinkler irrigations were applied when maximum crop evapotranspiration, determined based on class " $A$ " evaporation pan, indicated an accumulated value of $25 \mathrm{~mm}$. Results demonstrated that the increase in plant population increased leaf area index during the vegetative period. However, during the reproductive period the leaf area index was more affected by row spacing. The leaf area of individual plants, plant height and the number of nodes increased as plant population decreased. The legume height above soil surface presented a

${ }^{1}$ Engenheiro Agrônomo, MSc., Estudante do curso de Doutorado em Energia na Agricultura, Universidade Estadual Paulista (UNESP), Botucatu, SP.

${ }^{2}$ Engenheiro Agrônomo, PhD., Bolsista do CNPq, Professor Títular do Departamento de Engenharia Rural, Universidade Federal de Santa Maria (UFSM), 97105-900, Santa Maria - RS. E-mail: carlesso@ccr.ufsm.br. Autor para correspondência.

${ }^{3}$ Engenheiro Agrônomo, Programa de Mestrado em Agronomia, UFSM.

${ }^{4}$ Engenheiro Agrônomo, Programa de Mestrado em Engenharia Agrícola, UFSM. 
quadratic response in relation to plant population. The inter-node length was not affected by the different plant population and row spacing tested.

Key words: irrigation, crop system, drybean, mechanical harvest

\section{INTRODUÇÃO}

O crescimento e o desenvolvimento do feijoeiro dependem das características da cultivar e das condições de cultivo a que as plantas são submetidas. A população e o espaçamento entre plantas interferem na quantidade de água, luz e nutrientes utilizados pela cultura. Alterações morfológicas como altura das plantas, área foliar e ramificações formadas determinam a plasticidade da cultivar utilizada (BRADSHAW, 1965). As mudanças fisiológicas são menos evidenciadas do que a plasticidade morfológica das plantas de feijoeiro em determinados estágios de seu desenvolvimento e sob a influência das condições ambientais.

As cultivares de feijão podem ser classificadas em função do hábito de crescimento. Segundo o CIAT (1976), as cultivares dos tipos I e II são de porte ereto, arbustivo e ramificação fechada, sendo a primeira de crescimento determinado e a segunda indeterminado. De acordo com HARPER (1977), geralmente as plantas de hábito de crescimento determinado respondem ao desequilíbrio fisiológico causado pela densidade de população, por meio de mudanças no tamanho dos órgãos vegetativos e reprodutivos, enquanto plantas de crescimento indeterminado apresentam alterações no número desses órgãos.

Cultivares de feijoeiro do tipo II tendem a reduzir o número de nós com o aumento da população de plantas (CARPENTER \& BOARD, 1997). O incremento à população de plantas aumenta também o índice de área foliar do feijão. Porém, nessas condições, observa-se um declínio mais acentuado devido à antecipação da senescência das folhas (LUCAS \& MILBOURN, 1976). Para STONE \& PEREIRA (1994), quando se reduz a população, as plantas do feijão apresentam, individualmente, valores mais elevados de área foliar.

O desenvolvimento de cultivares de porte mais ereto, com a altura da primeira vagem mais elevada e com menor tendência ao acamamento, aliado a práticas adequadas de manejo são estratégias a serem utilizadas para possibilitar a utilização de mecanização direta ou semi-direta na colheita do feijoeiro. A irrigação e o correio manejo da densidade e espaçamento entre linhas podem auxiliar a obtenção de maior altura de plantas e de inserção das vagens, favorecendo a colheita mecanizada. A maioria das cultivares disponíveis no Brasil apresentam altura de inserção da primeira vagem entre 5 e $10 \mathrm{~cm}$, dificultando a prática da colheita mecanizada direta (ALONÇO \& ANTUNES, 1997). Dessa forma, este experimento foi conduzido com o objetivo de avaliar o comportamento de alguns parâmetros morfológicos das plantas, como índice de área foliar, altura das plantas, número de nós, comprimento dos entrenós e altura das vagens em relação à superfície do solo do feijoeiro irrigado por aspersão e submetido ao cultivo com diferentes populações de plantas e espaçamentos entre linhas de cultivo.

\section{MATERIAL E MÉTODOS}

O experimento foi conduzido em área experimental do Departamento de Engenharia Rural da Universidade Federal de Santa Maria - RS, em latitude de $29^{\circ} 42^{\prime} 24^{\prime \prime} \mathrm{S}$ e longitude de $53^{\circ} 48^{\prime} 42^{\prime \prime} \mathrm{W}$. O clima da região se enquadra na classe "Cfa", subtropical úmido, segundo a classificação de Köppen (MORENO, 1961). O solo do local é classificado como Podzólico vermelho-amarelo, pertencente à unidade de mapeamento São Pedro.

A adubação foi realizada de acordo com a análise química do solo e seguindo recomendações para a cultura do feijoeiro da COMISSÃO DE FERTILIDADE PARA SOLOS DO RS E SC (1995). Foram aplicados $100 \mathrm{~kg}$ de N.há ${ }^{-1}, 10 \mathrm{~kg} \mathrm{P}_{2} \mathrm{O}_{5}$ há $^{-1}$ e $40 \mathrm{~kg} \mathrm{~K}_{2} \mathrm{O}$ há $^{-1}$, na forma de ureia, super fosfato triplo e cloreto de potássio, respectivamente. O nitrogénio foi aplicado $1 / 3$ na semeadura e o restante em duas aplicações, realizadas aos 25 e 40 dias após a emergência das plantas (DAE).

A cultivar de feijão BR-FEPAGRO 44 Guapo brilhante, de crescimento indeterminado (tipo II) foi semeada no dia 17 de outubro de 1997. O cultivo foi realizado em sucessão à cultura do milho, em sistema de plantio direto. A cultura de ervilhaça (Vicia sativa L.) foi utilizada para cobertura do solo na entressafra. A emergência das plantas foi considerada quando, aproximadamente, $50 \%$ das plântulas haviam emergido, aos seis dias após a semeadura.

O experimento foi conduzido no delineamento experimental inteiramente casualizado, bifatorial (3 x 3$)$, com quatro repetições. As três populações de plantas utilizadas foram 175, 250 e 325 mil plantas há ${ }^{-1}$ e os três espaçamentos entre linhas de cultivo foram $35,50 \mathrm{e}$ $65 \mathrm{~cm}$. Estes valores são os que normalmente são utilizados pelos produtores (amplitudes mínima e máxima). As unidades experimentais apresentavam dimensões de $3 \times 4$ metros e as linhas de cultivo foram orientadas longitudinalmente no sentido Leste-Oeste.

A irrigação foi realizada por um sistema 
de aspersão convencional fixo. Irrigações foram aplicadas quando a evapotranspiração máxima da cultura indicava um valor acumulado de $25 \mathrm{~mm}$. A estimativa da evapotranspiração de referência foi obtida com base na evaporação do tanque classe "A" e do coeficiente de tanque. A evapotranspiração máxima da cultura foi determinada utilizando-se os valores estimados da evapotranspiração máxima e do coeficiente de cultura, propostos por DOORENBOS \& KASSAN (1979).

Aos dez DAE, foram selecionadas três plantas por parcela para as determinações não destrutivas de área foliar, altura de plantas, número de nós na haste principal e senescência das folhas, realizadas semanalmente até próximo à colheita das plantas. A área foliar das plantas foi determinada a partir da regressão linear ( $\mathrm{Y}=-3,3097+1,7883 \mathrm{X})$, obtida pelo produto do comprimento pela máxima largura da folha central do trifólio (variável independente), e a área foliar real do trifólio (variável dependente), determinada em mesa digitalizadora. $\mathrm{O}$ índice de área foliar foi determinado pela razão entre a área foliar fotossinteticamente ativa das folhas e a área de solo ocupada pela planta. A altura das plantas foi determinada pela distância vertical entre a superfície do solo até a inserção do trifólio do último nó vegetativo visível na planta. O número de nós foi obtido por contagem desde o nó cotiledonar até o último nó vegetativo da haste principal da planta. O comprimento dos entrenós foi obtido pela razão entre o número de nós e a altura da planta. A altura das vagens foi determinada, na colheita, medindo-se a distância entre a superfície do solo e a extremidade inferior da primeira vagem da plantas, em dez plantas por parcela.

A análise estatística dos resultados foi realizada utilizando-se o programa Statistical Analysis System (SAS). Determinaram-se a análise da variância e regressão dos resultados, em nível de significância de $5 \%$.

\section{RESULTADOS E DISCUSSÃO}

A evapotranspiração máxima acumulada dos 14 aos 94 DAE das plantas foi de $281,5 \mathrm{~mm}$. Nesse mesmo período, o total de precipitação pluvial ocorrido foi de $574 \mathrm{~mm}$, tendo sido aplicados $132 \mathrm{~mm}$ de água, através de cinco irrigações de aproximadamente $25 \mathrm{~mm}$. $\mathrm{O}$ montante das precipitações pluviais ocorrido no período foi elevado, devido à ocorrência do fenómeno El-Nino. No entanto, as precipitações foram irregularmente distribuídas. A época de menor ocorrência das precipitações e elevada insolação coincidiu com a fase de maior crescimento do dossel vegetativo (35 a 60 DAE).

$\mathrm{Na}$ tabela 1, são apresentados os resultados da análise da variância e de regressão
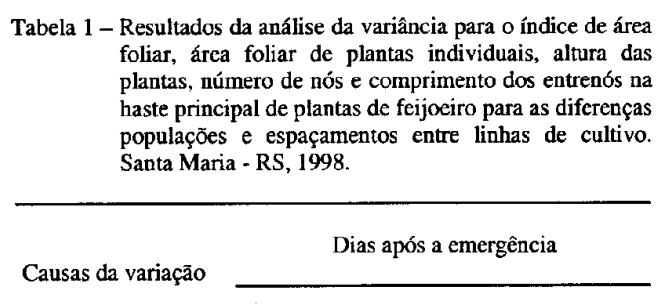

$\begin{array}{llllllllll}23 & 28 & 31 & 35 & 38 & 42 & 49 & 58 & 70 & 78\end{array}$

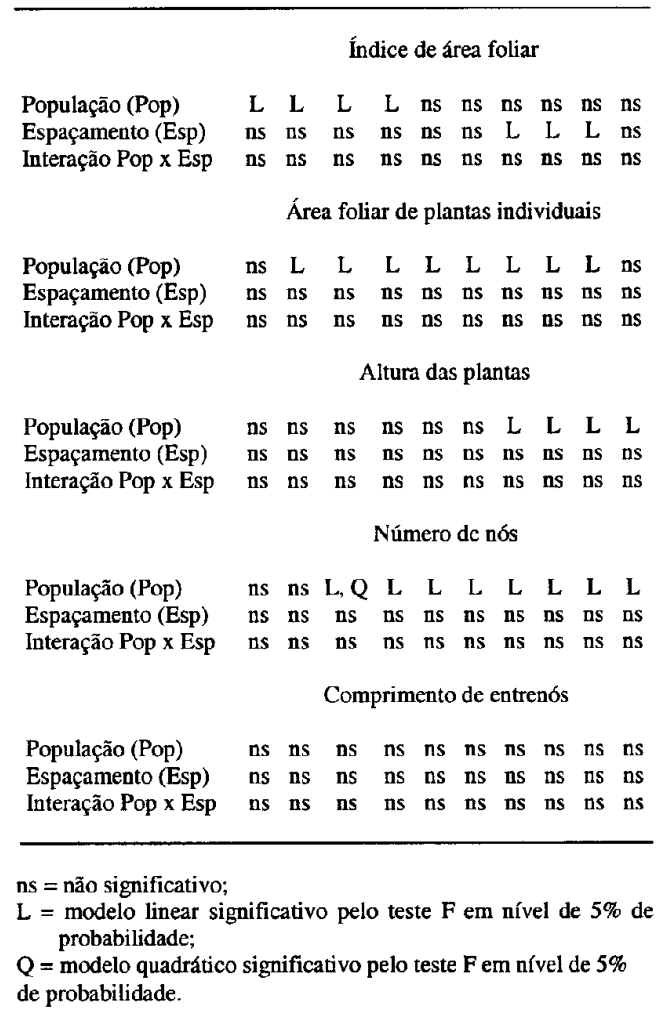

para o índice de área foliar, área foliar das plantas individuais, altura das plantas, número de nós e comprimento dos entrenós do feijoeiro. Os resultados não demonstraram efeito de interação entre a população de plantas e o espaçamento entre linhas de cultivo, para nenhuma das variáveis analisadas. Durante o estágio de crescimento vegetativo até a fase de pré-floração (35 DAE), o índice de área foliar aumentou com o incremento na população de plantas (Figura 1). De acordo com BRANDES et al. (1973), isso ocorre porque o índice de área foliar é função da área foliar da planta e da superfície de solo a ela disponível. Assim, em maiores populações, ocorre uma maior razão entre esses fatores. Isso ocorre, porque o aumento da população permite um arranjo mais eqüidistante 


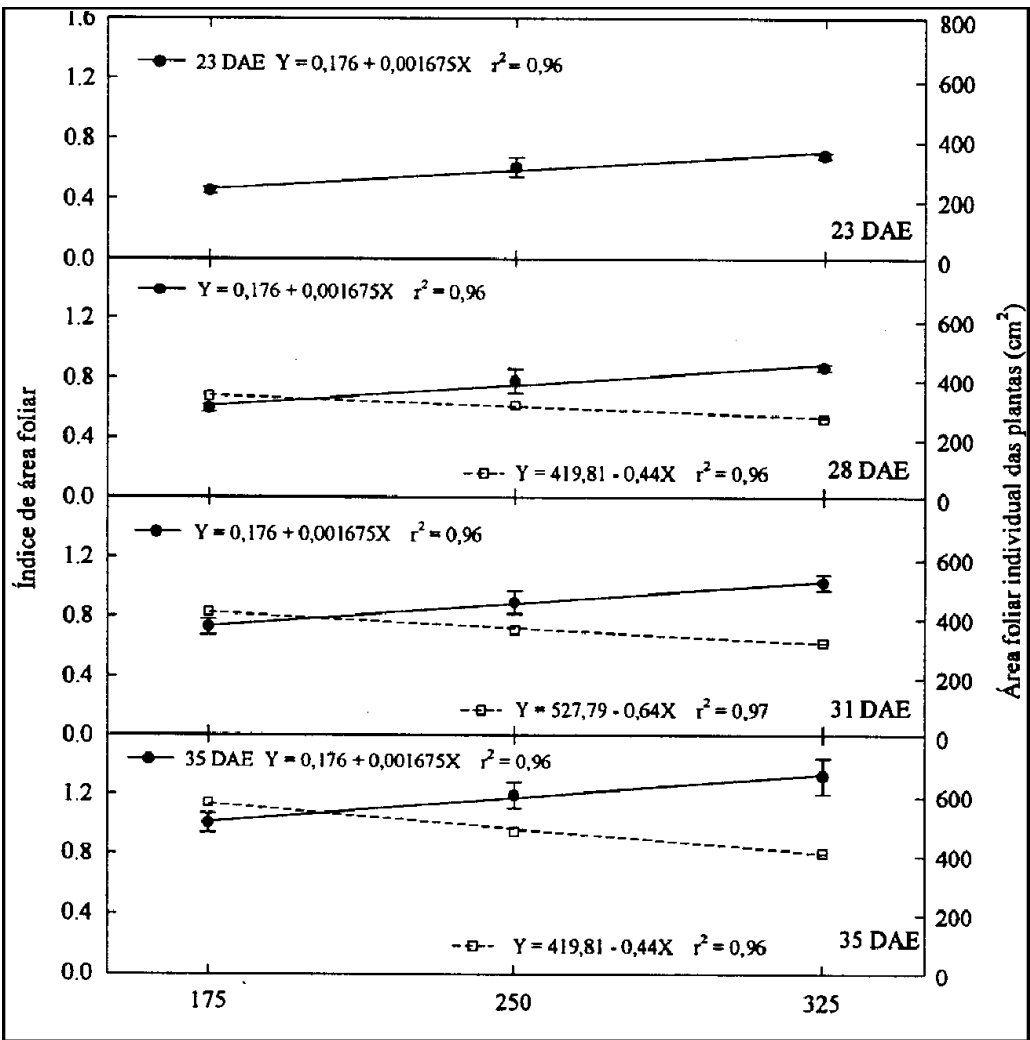

Figura 1 - Área foliar e índice do feijoeiro em relação às diferentes populações de plantas. As barras verticais representam o desvio-padrão. Santa Maria - RS, 1998. radiação solar interceptada durante o crescimento vegetativo do feijoeiro.

Observou-se uma inversão dos valores médios de área foliar de plantas individuais em relação ao índice de área foliar (Figura 1), com maior área foliar nas plantas cultivadas nas menores populações de plantas. Segundo PORTES (1996), a maior população de plantas implica maior índice de área foliar e, conseqüentemente, um ambiente de maior competição com menos radiação solar disponível para cada planta. $\mathrm{O}$ aumento da área foliar de plantas individuais é consequência direta da necessidade de compensação de espaços, visando a incrementar ao máximo sua área fotossinteticamente ativa. CROOKSTON et al. (1976) e PORTES \& CARVALHO (1993) verificaram que o aumento do sombreamento provocou redução da

entre plantas, de forma a reduzir a competição por recursos do ambiente, explorando de forma mais completa e eficiente uma determinada área do solo (MUNDSTOCK, 1977).

Do início de formação das vagens (49 DAE) até o enchimento de grãos (70 DAE), o índice de área foliar aumentou com o incremento do espaçamento entre linhas de cultivo (Figura 2) sem apresentar, no entanto, resposta significativa em relação à população de plantas (Tabela 1). O incremento no índice de área foliar com o aumento do espaçamento entre linhas de cultivo, nessa fase, pode ter sido motivado por uma aceleração na senescência das plantas cultivadas em espaçamentos menores. A ocorrência da área foliar máxima das plantas ocasiona maior autosombreamento do dossel das plantas. SOUZA \& ESCOBEBO (1997) concluíram que o balanço médio de radiação para o feijoeiro varia com o estádio fenológico e com o índice de área foliar. STEINMETZ et al. (1993) observaram aumento linear da

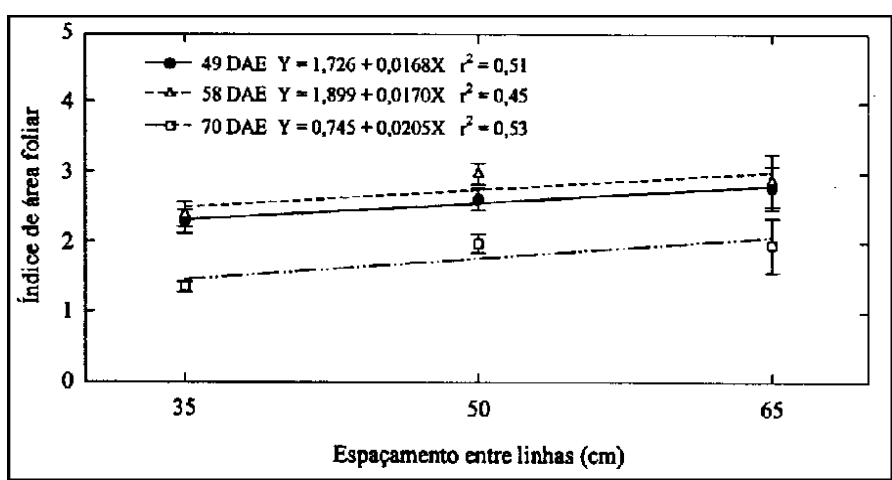

Figura 2 - Índice de área foliar do feijoeiro em relação aos diferentes espaçamentos entre linhas de cultivo. As barras verticais representam o desvio-padrão. Santa Maria - RS, 1998.

Ciência Rural, v. 30, n. 4, 2000. 


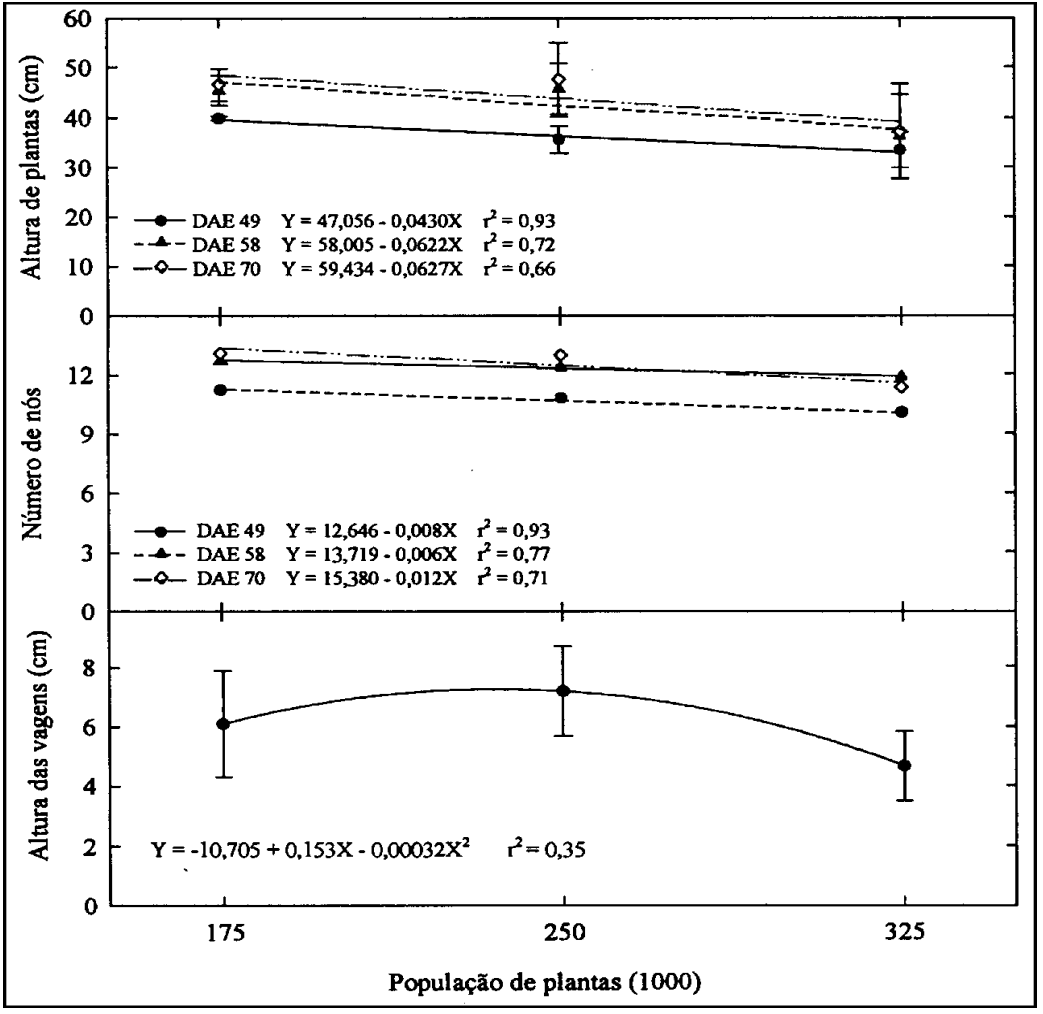

Figura 3 - Altura das plantas, número de nós e altura das vagens do feijoeiro em relação às diferentes populações de plantas. As barras verticais representam o desvio-padrão. Santa Maria - RS, 1998.

altura de plantas aumentou com a redução na população de plantas. Esse comportamento foi observado até a obtenção da máxima altura das plantas, aos 70 DAE (Figura 3). Não houve efeito significativo do espaçamento entre linhas de cultivo para a altura de plantas (Tabela 1). Em cultivares de feijoeiro do tipo II, como a utilizada neste experimento, é normal a ocorrência de crescimento, mesmo nos estádios mais avançados do ciclo, posteriores à fase de crescimento vegetativo. CUNHA \& SILVA (1978) e NIENHUIS \& SINGH (1985) também verificaram, para cultivares do tipo II, aumento na altura das plantas com a redução da população.

Deve-se considerar que as diferenças na altura das plantas (Tabela 1) foram observadas a partir do pleno florescimento das plantas (49 DAE), demonstrando que essa variável não foi significativamente afetada pela competição entre as plantas nas fases iniciais do desenvolvimento da cultura. WESTERMANN \& CROTHERS (1977) descrevem que o aumento da população de plantas aumenta a competição por fotoassimilados. Entretanto, em plantas de crescimento indeterminado, a partir do florescimento das plantas ocorre maior competição entre o crescimento vegetativo e o desenvolvimento dos órgãos reprodutivos. A maior altura das plantas com a redução na população indica que, dentro dos limites avaliados, o aumento da população de plantas não gerou um ambiente competitivo a ponto de causar estiolamento das plantas. ALCÂNTARA $\boldsymbol{e t} \boldsymbol{a}$. (1991) ressaltam que a elevação da população tende a causar o estiolamento das plantas, ocasionando acamamento.

Não houve efeito significativo do espaçamento entre linhas de cultivo para o número de nós na haste principal das plantas (Tabela 1). Entretanto, aos 31 DAE, houve resposta linear e quadrática para o número de nós em relação à população de plantas, apresentando máxima eficiência técnica para uma população de aproximadamente 260 mil plantas há ${ }^{-1}$. A partir dos 35 DAE, o número de nós decresceu linearmente com o aumento da população de plantas (Figura 3). Reduções do número de nós com o aumento da população de plantas foram também verificadas por DENIS \& ADAMS (1978) e COSTA et al. (1983).

Os resultados não indicaram alterações do comprimento dos entrenós na haste principal com a variação na população de plantas e espaçamento entre linhas de cultivo (Tabela 1). A redução da população ocasionou maior altura das plantas (Figura 3). Esse comportamento também foi observado para o número de nós na haste principal (Figura 3). Assim, a razão entre esses fatores não resultou em alterações expressivas no comprimento dos entrenós das plantas. NIENHUIS \& SINGH (1985), estudando cultivares de feijoeiro do tipo II em populações que variaram de 50 até 300 mil plantas há ${ }^{-1}$, não observaram diferenças no comprimento dos entrenós na haste principal da

Ciência Rural, v. 30, n. 4, 2000. 
planta. De acordo com esses autores, devido a sua elevada plasticidade, diferenças no comportamento dos entrenós são geralmente observadas em condições, nas quais a competição por luminosidade ocasiona o estiolamento das plantas.

A altura da extremidade da primeira vagem das plantas não foi afetada pelo espaçamento entre linhas de cultivo. Entretanto, a variação na população de plantas ocasionou um comportamento linear e quadrático significativo para a altura da extremidade da primeira vagem. A máxima eficiência técnica para a altura da extremidade da primeira vagem foi de $7,3 \mathrm{~cm}$ e foi observado para uma população de, aproximadamente, 235 mil plantas há ${ }^{-1}$ (Figura 3). De acordo com NIENHUIS \& SINGH (1985), em populações de aproximadamente 100 mil plantas há ${ }^{-1}$, ocorre elevada concentração de frutificação nos nós basais da haste principal. Porém, com o aumento da população, a frutificação concentra-se nos nós mais altos, elevando a posição das vagens em relação à superfície do solo. WILLAMIL LUCAS (1987) observou que a elevação da população de plantas aumenta a distância entre a extremidade da primeira vagem e a superfície do solo. Porém, de acordo com ALCÂNTARA $\boldsymbol{e t} \boldsymbol{a l}$. (1991), apesar da altura de inserção das vagens ser mais elevada em maiores populações, a verticalidade das plantas é reduzida, aproximando as vagens ao solo.

$\mathrm{O}$ cultivo da cultivar de feijoeiro BRFEPAGRO 44 - Guapo brilhante, irrigado por aspersão, nas populações de 175.000 a 325.000 plantas há ${ }^{-1}$ e nos espaçamentos entre linhas de cultivo de 35 a $65 \mathrm{~cm}$, não resultou em aumento expressivo na altura da extremidade da primeira vagem das plantas. As alturas das extremidades das vagens observadas não possibilitam a mecanização direta das atividades de colheita do feijoeiro, sem a ocorrência de perdas expressivas. Segundo SILVEIRA (1991), essa prática só é viável quando a distância entre o solo e a extremidade das vagens inferiores da planta for de aproximadamente $15 \mathrm{~cm}$. Em virtude dessa dificuldade para o emprego da colheita mecanizada direta, existem alguns equipamentos projetados para mecanizar algumas fases do processo de colheita, utilizando-se equipamentos como arrancador-enleirador e recolhedora-trilhadora em opções distintas. Contudo, segundo SILVA \& FONSECA (1996), para que as perdas sejam mínimas, as plantas devem apresentar características como porte ereto, boa altura da extremidade da primeira vagem em relação à superfície do solo, resistência à deiscência das vagens e ao acamamento das plantas.

\section{CONCLUSÕES}

A cultivar de feijoeiro BR-FEPAGRO 44 - Guapo brilhante, irrigada por aspersão, na população de 235 mil plantas há ${ }^{-1}$, apresenta maior altura da extremidade da primeira vagem em relação à superfície do solo, sendo ainda insuficiente para a implementação da colheita mecanizada direta.

A área foliar das plantas individuais e a altura das plantas do feijoeiro aumentam com a redução na população de plantas, e o índice de área foliar aumenta com o incremento da população das plantas e do espaçamento entre as linhas de cultivo.

O número de nós da haste principal do feijoeiro aumenta linearmente com a redução da população de plantas, e o comprimento médio dos entrenós não é afetado pela população e espaçamento de plantas.

\section{REFERÊNCIAS BIBLIOGRÁFICAS}

ALCÂNTARA, J.P., RAMALHO, M.A.P., ABREU, A.F.B., $\boldsymbol{e} t$ al. Avaliação de cultivares de feijão (Phaseolus vulgaris L.) em diferentes densidades de semeadura e condições de ambiente. Ciência e Prática, v.15, n.4, p.375-384, 1991.

ALONÇ, A. dos S., ANTUNES, I.F. Semeadura direta de feijão em resteva de trigo, visando à colheita mecanizada direta. Pesquisa Agropecuária Brasileira, Brasília, v.32, n.9, p.919-922, 1997.

ARAÚJO, A.G. de, BACK, N., LEAL, L.M.C. Desenvolvimento do projeto de uma colhedora-enleiradora de feijão para pequenos agricultores. Engenharia Rural, Piracicaba, v.8, n.l, p.65-73,1997.

BRADSHAW, A.D. Evolutionary significance as phenotypic plasticity in plant. Advances Genetics, v.13, p.115-155, 1965.

BRANDES, D., VIEIRA, C., MAESTRI, M., et al Efeito da população de plantas e da época de plantio no crescimento do feijoeiro (Phaseolus vulgaris L.) II - Análise de crescimento. Experientiae, Viçosa, v.15, n.1, p.1-21, 1973

BUTTERY, B.R. Analysis of the growth of soybeans as affected by plant population and fertilizer. Canadian Journal of Plant Science, Ottawa, v.49, p.675-684, 1969.

CARPENTER, A.C., BOARD, J.E. Growth dynamic factors controiling soybean yield stability across plant populations. Crop Science, Madison, v.37, p.1520-1526, 1997.

CIAT - CENTRO INTERNACIONAL DE AGRICULTURA TROPICAL. Condiciones de campo para realizar Ias evaluaciones del germoplasma del frijol. Cali, 1976. 1lp.

COMISSÃO DE FERTILIDADE DO SOLO-RS/SC Recomendações da adubação e calagem para os Estados do Rio Grande do Sul e de Santa Catarina. 3.ed. Passo Fundo: SBCS - Núcleo Regional Sul/Embrapa-CNPT, 1995. $223 p$.

COSTA, J.G.C., SHIBATA, J.K., COLIN, S.M. Plasticidade no feijoeiro comum. Pesquisa Agropecuária Brasileira, Brasília, v.18, n.2, p.159-167,1983.

CROOKSTON, R.K., TREHARNE, K.J., LUDFORD, P., et al

Ciência Rural, v. 30, n. 4, 2000. 
Response of bean to shading. Crop Science, Madison, v.15, p.412-416,1975.

CUNHA, J.M., SILVA, C.C. Estudo sobre fertilidade e densidade de semeio de feijão. In: EMPRESA DE PESQUISA AGROPECUÁRIA DE MINAS GERAIS. Projeto Feijão. Relatório 75/76. Belo Horizonte, 1978. p.16-19.

EMBRAPA-FEPAGRO. Uma nova cultivar de feijão para o Rio Grande do Sul - BR-FEPAGRO 44 - GUAPO BRILHANTE. Porto Alegre : Secretaria da Ciência e Tecnologia-RS, 1996. (Folheto).

HARPER, J.L. Population biology of plants. New York: Academic, 1977. 892p.

LUCAS, E.O., MILBOURN, G.M. The effect of density of planting on the growth of two Phaseolus vulgaris varieties in England. Journal of Agricultural Science, Cambridge, v.87, p.88-89, 1976 .

MOREnO, J.A. Clima do Rio Grande do Sul. Porto Alegre: Secretaria da Agricultura, Diretoria de Terras e Colonização, Secção de Geografia, 1961. 46p.

NIENHUIS, J., SINGH, S.P. Effects of location and plant density on yield and architectural traits in dry beans. Crop Science, Madison, v.25, n.4, p.579-584,1985.

PORTES, T.A. Ecofisiologia. In: ARAÚJO, R.S., RAVA, C.A., STONE, L.F., et al. Cultura do feijoeiro comum no Brasil. Piracicaba: POTAFÓS, 1996. p.101-137.

PORTES, T.A., CARVALHO, J.R.P. Área foliar, radiação solar, temperatura do ar e rendimento em consorciação e em monocultivo de diferentes cultivares de milho e feijão. Pesquisa Agropecuária Brasileira, Brasília, v.18, n.7, p.755$762,1983$.

POZZEBON, E.J., CARLESSO, R., KONIG, O., $\boldsymbol{e}$ t al. Acumulação de nutrientes no feijoeiro. Pesquisa Agropecuária Gaúcha, Porto Alegre, v.3, n.2, p.157$161,1997$.

SILVA, J.G., FONSECA, J.R. da. Colheita. In: ARAÚJO, R.S., RAVA, C.A., STONE, L.F. et al Cultura do feijoeiro comum no Brasil. Piracicaba: POTAPÓS, 1996. p.523-541.

SILVEIRA, G.M. da. As máquinas para colheita e transporte. São Paulo: Globo, 1991. 183p.

SOUZA, J.L., ESCOBEBO, J.F. Balanço de radiação em cultivos de feijão-vagem com e sem cobertura de polietileno. Pesquisa Agropecuária Brasileira, Brasília, v.32, n.1, p.112,1997

STEINMETZ, S., SILVEIRA, E.P., ANTUNES, I.F. Aproveitamento da radiação solar interceptada pelo feijoeiro em função do tipo de plantas e da adubação nitrogenada. In: REUNIÃO TÉCNICA ANUAL DO FEIJÃO E OUTRAS LEGUMINOSAS DE GRÃOS ALIMENTÍCIOS, 26, 1993, Santa Maria, RS. Atas e Resumos... Santa Maria, RS, 1993. p.92-93.

STONE, L.P., PEREIRA, A.L. Sucessão arroz-feijão por aspersão. Efeitos de espaçamento entre linha, adubação e cultivar no crescimento, desenvolvimento radicular e consumo d'água do feijoeiro. Pesquisa Agropecuária Brasileira, Brasília, v.29, n.6, p.939-954,1994.
DENIS, J.C., ADAMS, M.W. A factor analysis of plant variables related to yield in dry beans. I. Morphological traits. Crop Science, Madison, v.18, p.74-78,1978.

DOORENBOS, J., KASSAN, A.H. Efectos del água el rendimento de los cultivos. Roma: FAO, 1979. 212p. (Riego y drenage,33).

WESTERMANN, D.T., CROTHERS, S.E. Plant population effects on the seed yield components of beans. Crop Science, Madison, v.17, p.493-496,1977.

WILLAMIL LUCAS, J.M. Influência da densidade de população sobre a produção em variedade de feijão vagem (Phaseolus vulgaris L.) de porte baixo. Piracicaba, SP, 1987. 69p. Dissertação (Mestrado) - ESALQ Universidade de São Paulo, 1987.

Ciência Rural, v. 30, n. 4, 2000. 